\title{
A comparative study between adolescent and adult patients with pilonidal sinus disease
}

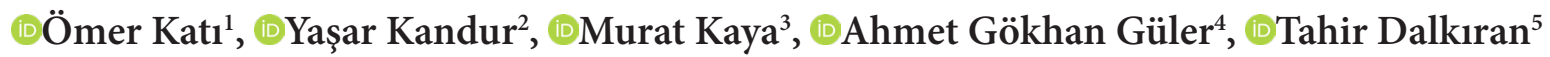 \\ ${ }^{1}$ Department of Pediatric Surgery, Necip Fazıl City Hospital, Kahramanmaraş, Turkey \\ ${ }^{2}$ Department of Pediatrics, School of Medicine, Kırıkkale University, Kırıkkale, Turkey \\ ${ }^{3}$ Department of General Surgery, Necip Fazıl City Hospital, Kahramanmaraş, Turkey \\ ${ }^{4}$ Department of Pediatric Surgery, Kahramanmaraş Sütçü İmam University, Kahrmanmaraş, Turkey \\ ${ }^{5}$ Department of Pediatrics, Necip Fazıl City Hospital, Kahramanmaraş, Turkey
}

Cite this article as: Katı Ö, Kandur Y, Kaya M, Güler AG, Dalkıran T. Flap versus primary closure for treatment of pilonidal sinus disease: a comparative study between adolescent and adult patients. Anatolian Curr Med J 2021; 3(2); 136-139.

\begin{abstract}
Objectives: The main targets of the treatment modalities for pilonidal sinus are to prevent recurrences, and to increase the quality of life. It is unknown whether there is a different treatment trend in pediatric patients as compared with adults. In this study, we aimed to evaluate the surgical methods in pediatric and adult patients with pilonidal sinus.

Material and Method: This retrospective study was conducted at the Departments of Pediatric Surgery and General Surgery Department of Necip Fazıl City Hospital, Kahramanmaraş from 2013 to 2017. A total of 66 pediatric patients and 68 adult patients were enrolled in this study.

Results: The number of pediatric patients was significantly higher than adults in mean of flap closure (21 (31.8\%) vs $2(2.9 \%)$, $\mathrm{p} \leq 0.01)$. However, primary closure was the most preferred method both in pediatric and adult patients, $45(68.2 \%)$ pediatric patients and $63(92.6 \%)$ adults. During a postoperative follow-up period of 1 month, $10(15.2 \%)$ pediatric patients and $12(17.6 \%)$ adult patients developed wound infections $(\mathrm{p}=0.21)$. There was no significant difference between pediatric and adult patients with respect to mean recurrence rate (pediatric $=8(\% 12.1)$ vs adult $=9(\% 13.2)(\mathrm{p}=0.527))$.

Conclusion: We believe that pediatric surgeons should increase their interest in treatment options of PS disease since its prevalence increases in pediatric age group especially in adolescents in recent years. Besides, there was a female prepondarance in pediatric patiens.
\end{abstract}

Keywords: Pilonidal sinus, flap, pediatric, adult

\section{INTRODUCTION}

Pilonidal sinus (PS) disease is usually seen in young age group, commonly between 17 and 38 years of age (1). The estimated prevalence is 26 per 100.000 people, affecting men 2 to 4 times as much as women $(2,3)$. It was long considered that PS is predominantly a genetic disease (4).Today, PS is accepted as an acquired lesion in the natal cleft that results from burrowing of loose hair shafts into the distended hair follicles, that leads a suppurative sinus filled with hair $(5,6)$. The nature of hairs, force of implantation, and vulnerability of the skin are important factors in the development of PS. Since overweight people have deeper inter-gluteal grooves and excessive hair they are more commonly affected(7).
The main target of the treatment modalities of PS are to prevent recurrences, and to increase the quality of life.There are different treatment modalities including letting the area open after excision, primary total or partial closure, closure with flap, injection of a sclerosing agent, destruction of sinus tract by heat or freezing cold application (8-10).In recent years the prevalence of PS in pediatric patients has been increasing (11). It is unknown whether there is a different treatment trend in pediatric patients as compared with adults.In this study, we aimed to compare the efficacy of the Limberg flap and tension-free primary closure between pediatric and adult patients. 


\section{MATERIAL AND METHOD}

This retrospective study was conducted at the Departments of Pediatric Surgery and General Surgery of Necip Fazıl City Hospital, Kahramanmaraş from 2013 to 2017. The study was carried out with the permission of Ethics Committee of Sütçü İmam University (permission granted: 16.05.2018, decision no: 06). The trial was conducted in accordance with the Helsinki Declaration principles. All of the patients who were operated on for sacrococcygeal PS were included in this study. A total of 66 pediatric patients and 68 adult patients were enrolled. All of the patients' age, gender, operational technique, and recurrence rate were recorded. Study data were analyzed using SPSS 17 (SPSS Inc., Chicago, IL, USA) software package. Descriptive analysis was done for demographic variables. Chi-square test was used for quantitative variables.

Patients were operated either by excision and reconstruction with the Limberg flap, primary closure, or marsupialization. The mean follow-up period was 20 months (range 6-42 months)to monitor surgical complications of the treatment, including post-operative infection and recurrence.

\section{RESULTS}

Overall, 50 (75.7\%) of the pediatric patients and 12 (17.6\%) of the adults were female. The two groups were significantly different with respect to gender distribution $(\mathrm{p}<0.01)$. The median age of the pediatric group was 14.4 years (range 12-17 years) and 24 years (range 18-53 years) of the adult group.The number of pediatric patients undergoing flap closure was significantly higher than adults $(21(31.8 \%)$ vs $2(2.9 \%), \mathrm{p} \leq 0.01)$. However, primary closure was the most preferred method both in pediatric and adult patients, 45 (68.2\%) pediatric patients and 63 (92.6\%) adults.Although 3(4.4\%)adult patients underwent marsupialization, none of the pediatric patients were treated with this method. There was no significant difference between pediatric and adult patients in terms of the mean recurrence rate (pediatric group $8(12.1 \%) v s$ adult group $9(13.2 \%)(\mathrm{p}=0.527))$. There was no recurrence in patients undergoing flap closure. No post-operative complication other than wound infection developed in a total of 17 patients. They were treated with oral antibiotics. There was no significant difference between the groups in terms of the mean complication rate. During a postoperative follow-up period of 1 month, $10(15.2 \%)$ pediatric patients and $12(17.6 \%)$ adult patients developed wound infections $(\mathrm{p}=0.21)$. Seven $(15.5 \%)$ pediatric patients with primary closure and $3(14.2 \%)$ with flap closure developed wound infection $(\mathrm{p}=0.893)$. Eight (12.1\%) pediatric patients and $9(13.2 \%)$ adult patients developed recurrence $(\mathrm{p}=0.527)$. Two $(9.5 \%)$ pediatric patients with flap closure and $6(13.3 \%)$ with primary closure developed recurrence $(\mathrm{p}=0.650)$.

\section{DISCUSSION}

The incidence of PS disease varies between populations. It is more common among people from Mediterranean countries (11). Pilonidal sinus has been increasing in recent years in pediatric population (12). In our opinion, the predisposing factors area history of local trauma due to excess body weight and increased hormonal factors in adolescence. Especially childhood obesity has reached epidemic levels in developed as well as in developing countries in recent decades (13).

Although the female/male ratio varies in many studies, it ranges between $1 / 2$ and $1 / 6(14,15)$. Our results showed a girl preponderance in pediatric age group but a male preponderance in adult group. It is already known that the primary mechanism in the etiology of PS is the attachment of hair follicles to the epithelium of the deep intergluteal sulcus (6). We believe that this difference in the pediatric age group caused by the fact that female adolescents enter puberty earlier than boys; thus, local hair formation occurs earlier.In addition, hormonal changes starting with pulsatile secretion of $\mathrm{GnRH}$ (Gonadotropin releasing hormone) in adolescent girls is a major reason of the girl preponderance in the pediatric age groups since increased androgen hormones will affect pilosebaceous glands. As a result of late hormonal activity onset among boys, the process of sinus formation can occur after pediatric age (16).

Although different surgical methods have been proposed,there is no agreed optimal surgical procedure. The preference of the surgery type is dependent on patient specific factors and the width of the sinus area.Although we select the primary closure method mostly in both of pediatric and adult groups, the number of patients undergoing flap reconstruction in pediatric age group was significantly higher than the adult group. However various researchers have concluded that flap reconstruction was superior to excision and primary closure for PS (17) while other studies find no superiority (4).

Flap repair prevents tension of the wound and midline scar tissue. Recent studies have shown that recurrence rates for flap repair were very low in comparison to conventional primary closure (0-3\% vs $7 \%$ to $42 \%)$ $(18,19)$. Shabbir et al. (20) compared flap and primary closure in 60 adults. They found that flap closure have a advantage of 1.5 times less infection rate and 4 times less recurrence rate. In our study, we found no significant difference between the techniques in pediatric age group. We explained it by our shorter follow up period.

There was no significant difference between the adolescents and adults in terms of complications in our study. On the other way a recent study (21) found a higher incidence of complications (wound infection and recurrence) in pediatric age group compared with our study. We explained this conflict by the longer follow up period (median follow up 13 month). 
Table 1. Comparison of pediatric and adult patients

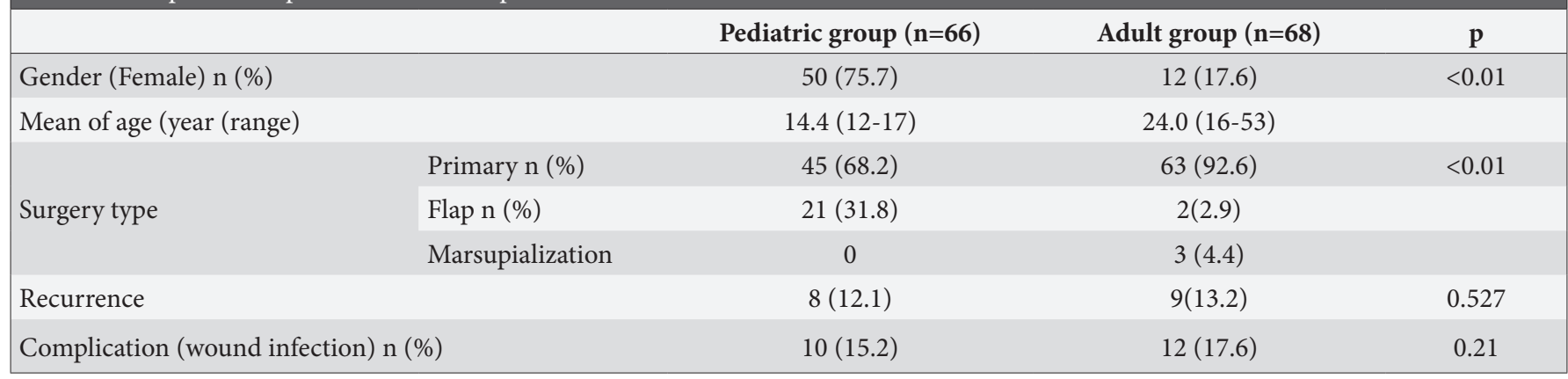

An important conflict was the high rate of primary closure in adults. This study is not a concurrent prospective study. The technique was chosen according to the preference of the surgeon.

We are aware of the limitations. It was not possible to compare the lifestlye in the two groups. Additionally the indication for using a flap or doing a primary closure was subjective. Primary closure was preferered in small PS and flap large PS, especially in adolescents. Morover sinceour study was a retrospective study we were not able to compare the BMI values of the patients. Finally, our study deployed a relatively small sample size.

\section{CONCLUSIONS}

We are of the opinion that pediatric surgeons should increase their interest in treatment options of PS disease since its prevalence increases in pediatric age group especially in adolescents in recent years, due to increase of prevalence of obesity in children. Besides, there was a female prepondarance in pediatric patiens.

\section{ETHICAL DECLARATIONS}

Ethics Committee Approval: The study was carried out with the permission of Ethics Committee of Sütçü İmam University (permission granted: 16.5.2018, decision no: 06).

Informed Consent: Because the study was designed retrospectively, no written informed consent form was obtained from patients.Referee Evaluation Process: Externally peer-reviewed.

Conflict of Interest Statement: The authors have no conflicts of interest to declare.

Financial Disclosure: The authors declared that this study has received no financial support.

Author Contributions: All of the authors declare that they have all participated in the design, execution, and analysis of the paper, and that they have approved the final version.

\section{REFERENCES}

1. Shah A Waheed A, Malik A. Recurrence rates in pilonidal sinus surgery comparison of twotechniques (Karydak is versus conventional open excision). Pak J Med Health Sci 2009; 3: 41-8.

2. McCallum I, King PM, Bruce J.Healing by primary versus secondary intention after surgical treatment for pilonidal sinus. Cochrane Database Syst Rev 2007; 17: CD006213

3. Saydam M, Şahin M, Female sacrococcygeal pilonidal sinus features and EQ-5D life quality survey and body image survey results: a clinical study, Anatolian Curr Med J 2021; 3; 31-5

4. Aldemir M, Kara IH, Erten G et al.Effectiveness of collagenase in thetreatment of sacrococcygeal pilonidal sinüs disease. Surg Today 2003; 33: 106-9.

5. Chintapatla S, Safarani N, Kumar S et al. Sacrococcygeal pilonidal sinus: historical review, pathological insight and surgical options. Tech Coloproctol 2003; 7: 3-8

6. daSilva JH. Pilonidalcyst: cause and treatment. Dis Colon Rectum 2000; 43: 1146-56

7. Rafi Y, Butt TM, Rehman HA, Rafiq K, Chaudhary AM. Pilonidal disease: a conservative approach to the problem. AnnKing Edward Med Uni 2001; 7: 83-4.

8. Hegge HGJ Vos GA, Patka P, Hoitsma HF. Treatment of complicated or infected pilonidal sinüs disease by local application of phenol. Br J Surg 1987; 102: 52-4

9. Mersh GA. Pilonidalsinus: finding the right tract for treatment. Br J Surg1990; 77: 123-32,

10. Stephens FO, Stephens RB.Pilonidal sinus: management objectives. Aust N Z J Surg. 1995; 65: 558-60.

11. Yildiz T, Elmas B, Yucak A, Turgut HT, Ilce Z. Risk factors for pilonidal sinus disease in teenagers. Indian J Pediatr.2017; 84: 134-8.

12. Stites T, Lund DP. Common anorectal problems. Semin Pediatr Surg 2007;16:71-8

13. Sahoo K, Sahoo B, Choudhury AK, Sofi NY, Kumar R, Ajeet Bhadoria AS. Childhood obesity: causes and consequences. J Family Med Prim Care. 2015; 4: 187-192.

14. Harlak A, Menteș Ö, Kilic S, Coskun K, Duman A, Yılmaz F. Sacrococygeal pilonidal disease: analysis o previously proposed risk factors. Clinics 2010; 65 : 125-31.

15. Yılmaz M, Can MH, Sevinç MM, Yiğit G, Keskin Ö.Sacrococcygeal Pilonidal Disease is Associated with Increased Body Weight, High Body-Mass Index and Skin Color in Young Men. Kolon Rektum HastDerg 2008; 18 : 14-20.

16. Serour F, Somekh E, Krutman B, Gorenstein A.Excision with primary closure and suction drain age for pilonidal sinus in adolescent patients. Pediatr SurgInt2002; 18: 159-61. 
17. Ertan T, Koc M, Gocmen E, Aslar AK, Keskek M, Kilic M. Does technique alter quality of life afterpilonidal sinus surgery? Am J Surg2005; 190: 388-92.

18. Muzi MG, Milito G, Nigro C, et al. A modification of primary closure for thetreatment of pilonidal disease in day-caresetting. ColorectalDis2009; 11: 84-8.

19. Akca T, Colak T, Ustunsoy B, Kanik A, Aydin S. Randomized clinical trial comparing primary closure with the Limberg flap in the treatment of primary sacrococcygeal pilonidal disease. $\mathrm{Br}$ J Surg. 2005; 92: 1081-4.

20. Shabbir F, Ayyaz M, Farooka MW, Toor AA, Sarwar H, Malik AA. Modified Limberg's flap versus primary closure for treatment of pilonidal sinüs disease: A comparative study. 2014;. 64: 1270-3.

21. Braungart S, Powis M, Sutcliffe JR, Sugarman ID. Improving outcomes in pilonidal sinus disease. J Pediatr Surg 2016; 51:2824. 